\title{
Frequency of Congenital Anomalies in Newborns and Its Relation to Maternal Health in a Tertiary Care Hospital in Peshawar, Pakistan
}

Adnan Khan, ' Muhammad Zuhaid, ${ }^{2}$ Maria Fayaz,' Faryal Ali,' Arsalan Khan,' Raza Ullah, ' Javariya Zafar, ${ }^{1}$ Hakeem Ullah,' Saiqa Baloch,' Sanam Gandapur.'

\begin{abstract}
Background: Congenital anomalies are a major cause of perinatal and neonatal deaths, both in low- and high-income countries. They are relatively common worldwide, affecting $3 \%$ to $5 \%$ of live births. Methods: A cross-sectional study was conducted from January 2014 to June 2014 at the Khyber teaching hospital in Peshawar. Specific patient information was obtained from patient records at the beginning of the study. Those individuals found to have at least one birth defect were approached and their attendants (mothers) were interviewed. Information regarding various risk factors was collected. Descriptive analyses were carried out. Results: Out of 1062 deliveries, 2.9\% (31) of newborns had various congenital anomalies. Hydrocephalus (22.6\%), anencephaly (12.9\%), and spina bifida (9.7\%) were major anomalies. The maternal age ranged from 18 years to 46 years (mean: $30 \pm 8$ ). Most of the anomalies (35.5\%) were present in the $26-30$ years age group. Out of 31 babies, $6.4 \%$ had multiple anomalies. The preponderance of various congenital anomalies was seen in parity 1 (35.4\%); parities 2 to 4 had lower incidences $(35.4 \%)$. The consanguinity rate was $67.7 \%$; only $32.3 \%$ of patients were using folic acid. History of passive smoking was positive in $16.1 \%$ of cases. Conclusion: Anencephaly and hydrocephalus were the most prominent anomaly detected; early prenatal diagnosis may be helpful in decreasing mortality by offering early termination. Low intake of folic acid and a high consanguinity rate were the most common associated risk factors for congenital anomalies. These risk factors may be reduced by creating awareness regarding the avoidance of consanguineous marriage and promoting the use of folic acid during pregnancy.
\end{abstract}

Keywords: Congenital Abnormalities, Nervous System Malformations, Neural tube defects, Folic acid, Consanguinity (Source: MeSH-NLM).

About the Author: Adnan Khan is a fifth-year medical student of a five-year MBBS program at Rehman Medical College, Peshawar. Pakistan.
Submission: Jan 17, 2015

Acceptance: Mar 9, 2015

Publication: Mar 24, 2015

Process: Peer-reviewed

\section{Introduction}

Boygle defines a birth defect in his study as abnormalities of structure and function or metabolism that are present at birth and result in physical, mental disability, and even mortality. ${ }^{1}$ Birth defects represent a prenatal origin of disorders that can be caused by a defect in a gene, chromosomal disorders, environmental teratogens, and micronutrient deficiencies. Rubella, diabetes mellitus, folic acid and iodine deficiency, medicinal and recreational drug exposure including tobacco and alcohol, and certain environmental chemicals and radiation are all other factors that cause birth defects (World Health Organization, Available from: http://apps.who.int/gb/ebwha/pdf_files/EB126/B126_10-en. pdf, updated 2015 March 3; cited 2015 March 11).

The rapid decline in infant mortality and morbidity in high-income countries has focused the attention of pediatricians to the problem of congenital anomalies. In the past, the causes of infant mortality were primarily related to infectious diseases. This tendency has been transmuted by antibodies and advances in the field of preventative medicine and immunology such that death in infancy is now more commonly due to congenital anomalies (CAs). ${ }^{2}$ CAs are a major cause of perinatal and neonatal death in low- to high-income countries.
Each year, 7.9 million children (6\% of total births worldwide) are born with a serious anomaly of hereditary origin. ${ }^{3}$ In the United States (US), CAs are reported at a prevalence of $3 \%$ to $5 \%$ of live-births; ${ }^{2}$ the prevalence in Europe is reported as 2.1\% (EUROCAT, European Network of Congenital Anomaly Registers, Available from: http://www.eurocat-network.eu/, updated 2015; cited 2015 Jan 17). In India, congenital anomalies account for $8 \%$ to $15 \%$ of perinatal deaths and $13 \%$ to $16 \%$ of neonatal deaths. ${ }^{4}$

In Pakistan, approximately $6 \%$ to $9 \%$ of perinatal deaths are attributed to congenital malformations. ${ }^{5}$ of these, approximately $40 \%$ to $60 \%$ of congenital anomalies are of unknown etiology, $20 \%$ are attributed to a combination of heredity and other factors, $7.5 \%$ are attributed to single gene mutations, $6 \%$ are caused by chromosomal abnormalities, and another $5 \%$ are due to maternal illnesses such diabetes mellitus or infection. ${ }^{6}$ Furthermore, low socio-economic status and low literacy rate are other components of high significance in a population.?

Since there have been no recent studies evaluating congenital anomalies in Peshawar, our aim is to discover the frequency of various congenital abnormalities in neonates born at Khyber teaching hospital in Peshawar. An additional aim of the study is to elicit CA associations with various risk factors.

${ }^{1}$ Undergraduate student (MBBS). Rehman Medical College, Peshawar, Pakistan.

${ }^{2}$ Internal Medicine Resident. Rehman Medical College, Peshawar, Pakistan. 


\begin{abstract}
Methods
A descriptive, cross-sectional study was conducted at the obstetrics and Gynecology Department at Khyber Teaching Hospital in Peshawar, Pakistan from January 2014 to May 2014. Khyber Teaching Hospital is a tertiary care hospital in Peshawar that attends to the Khyber Pukhtoonkwa Province's population. In our study, we included all those infants who were diagnosed with at least one birth defect. Information regarding patients was obtained from patient records at the beginning of the study. Mothers of all those infants with congenital anomalies were approached and interviewed and information regarding various risk factors was collected on a pre-designed pro forma. Similar to a previous study, 13 the questionnaire was divided into four sections: The first section of our questionnaire included the demographic data of the child while the second part dealt with the medical history of the child's parents which included comorbidities, gestational age, gestational period, paternal age, and occupation and education level of the mother. The third part of the questionnaire consisted of a series of yes/no questions regarding various risk factor exposures. Finally, the last section identified the specific CA.
\end{abstract}

Statistical analysis was performed using the Statistical Package for Social Science (SPSS $\odot$ ) version 20. Continuous data was displayed as the mean \pm standard deviation (SD), while the categorical and nominal data were presented as frequencies and percentages.

The Ethical Review Board of Rehman Medical College in Peshawar, Pakistan approved the study on 1st January 2014. The guidelines of the Strengthening of the Reporting of Observational Studies in Epidemiology (STROBE) statement checklist was followed in creating the present article. ${ }^{8}$

\section{Results}

Out of 1062 deliveries, 31 (2.9\%) newborns had various congenital anomalies. Hydrocephalus (22.6\%), anencephaly (12.9\%), spina bifida $(9.7 \%)$, meningocele $(6.5 \%)$, microcephaly $(6.5 \%)$, and cleft lip $(6.5 \%)$ were the commonest congenital anomalies. The distribution of the various congenital anomalies is shown in Table 1.

Out of 31 newborns, $29(93.5 \%)$ had single anomalies and two $(6.4 \%)$ had multiple anomalies. Seventeen $(54.8 \%)$ were male and $14(45.2 \%)$ were female $(p=0.29)$. The maternal age ranged from 18 years to 46 years with a mean of $30 \pm 8$ years. The majority of the anomalies (35.5\%) were present in the age group of 26-30 years. The majority of the newborns (77.6\%) had birth weights in the range of 2.4 to $4 \mathrm{~kg}$. The consanguinity rate was $67.7 \%$; only $32.3 \%$ of mothers were taking folic acid. Three $(9.6 \%)$ patients were on treatment for diabetes mellitus ( 1 on insulin and 2 on oral hypoglycemic medications), and two (6.4\%) patients were being treated for hypertension. A history of passive smoking was positive in five $(16.1 \%)$ cases (Table 2 ).

In terms of the maternal gravida status, 6 (19.3\%) mothers were primigravida, 22 (70.9\%) mothers were multi gravida, and $3(9.6 \%)$ mothers were grand-multi gravida. The proportion of various congenital anomalies in parity 1 was $35.4 \%$ and the proportion of anomalies in parities 2 to 4 was $35.4 \%$ (Table 3).
Table 1. Distribution of Congenital Malformations in Newborns.

\begin{tabular}{|lcc|}
\hline Congenital anomalies & Frequency $(\mathrm{n}=31)$ & $\%$ \\
\hline Hydrocephalous & 7 & $22.6 \%$ \\
\hline Anencephaly & 4 & $12.9 \%$ \\
\hline Spina bifida & 3 & $9.7 \%$ \\
\hline Meningocele & 2 & $6.5 \%$ \\
\hline Microcephaly & 2 & $6.5 \%$ \\
\hline Cleft lip & 2 & $6.5 \%$ \\
\hline Ambiguous genitalia & 1 & $3.2 \%$ \\
\hline Dilated abdomen & 1 & $3.2 \%$ \\
\hline Duodenal atresia & 1 & $3.2 \%$ \\
\hline Dyonophic, dilated abdomen & 1 & $3.2 \%$ \\
\hline Castrochiasis & 1 & $3.2 \%$ \\
\hline Hydrocele/kidney not palpable & 1 & $3.2 \%$ \\
\hline Meningomycele & 1 & $3.2 \%$ \\
\hline Spina bifida, cleft lip, palette & 1 & $3.2 \%$ \\
\hline Telepies aquina varacele & 1 & $3.2 \%$ \\
\hline Telepies left foot & 1 & $3.2 \%$ \\
\hline
\end{tabular}

Table 2. Demographic Details and Major Characteristics.

\begin{tabular}{|c|c|c|}
\hline Characteristics & Frequency $(n=31)$ & $\%$ \\
\hline \multicolumn{3}{|l|}{ Newborn Weight } \\
\hline $1-2.4 \mathrm{~kg}$ & 7 & $22.6 \%$ \\
\hline $2.5-4 \mathrm{~kg}$ & 24 & $77.6 \%$ \\
\hline$>4 \mathrm{~kg}$ & 0 & $0 \%$ \\
\hline \multicolumn{3}{|l|}{ Newborn Sex } \\
\hline Male & 17 & $54.8 \%$ \\
\hline Female & 14 & $45.2 \%$ \\
\hline \multicolumn{3}{|l|}{ Maternal Age } \\
\hline $15-20$ & 3 & $9.7 \%$ \\
\hline $21-25$ & 5 & $16.1 \%$ \\
\hline $26-30$ & 11 & $35.5 \%$ \\
\hline $31-35$ & 4 & $12.9 \%$ \\
\hline $36-40$ & 2 & $6.5 \%$ \\
\hline$>40$ & 6 & $19.4 \%$ \\
\hline \multicolumn{3}{|l|}{ Paternal Age } \\
\hline $20-25$ & 8 & $25.8 \%$ \\
\hline $26-30$ & 8 & $25.8 \%$ \\
\hline $31-35$ & 6 & $19.4 \%$ \\
\hline $36-40$ & 2 & $6.5 \%$ \\
\hline$>40$ & 7 & $22.6 \%$ \\
\hline \multicolumn{3}{|l|}{ Consanguinity } \\
\hline Yes & 21 & $67.7 \%$ \\
\hline No & 10 & $32.3 \%$ \\
\hline \multicolumn{3}{|l|}{ Folic acid use } \\
\hline Yes & 10 & $32.3 \%$ \\
\hline No & 21 & $67.7 \%$ \\
\hline \multicolumn{3}{|l|}{ Smoking History } \\
\hline Yes & 0 & $0 \%$ \\
\hline No & 26 & $83.9 \%$ \\
\hline Passive & 5 & $16.1 \%$ \\
\hline
\end{tabular}


Table 3. Maternal Parity.

\begin{tabular}{lcc}
\hline Parity & Frequency $(\mathrm{n}=31)$ & $\%$ \\
\hline 0 & 3 & $9.7 \%$ \\
\hline 1 & 11 & $35.5 \%$ \\
$2-4$ & 11 & $35.5 \%$ \\
5 or more & 6 & $19.4 \%$ \\
Total & 31 & $100 \%$ \\
\hline
\end{tabular}

\section{Discussion}

Major CAs occur in approximately $2 \%$ to $3 \%$ of births with a variable frequency in different populations. ${ }^{9}$ Congenital malformations or birth defects may be detected soon after birth or later, depending upon the nature of the defect. Congenital malformations are significantly contributing to infant mortality and morbidity; high-income nations have devised precise observation frameworks to discover the prevalence of CAs for the development of effective preventive systems. ${ }^{10}$

The frequency of CAs in our own hospital deliveries (2.91\%, $29.19 / 1000$ total births) is much higher compared to other local hospitals. For example, a study done in Kohat reported a frequency of 9.7/1000 live births," and another study in Karachi demonstrated a frequency of 11.4/1000 live births. ${ }^{12}$ Data from a hospital-based study in India reported a frequency of congenital anomalies at $1.91 \% .{ }^{13}$ Interestingly, our data corresponds to findings in Iran that report a frequency of congenital anomalies at $29.4 / 1000$ live births. ${ }^{14}$ This is also similar to a study done in Canada (36.18/1000). ${ }^{15}$

In our study, the CAs related to the central nervous system (CNS) were the most common (58.06\%). CNS anomalies included meningomyelocoele, anencephaly, and hydrocephalus, among others. Some cases of hydrocephalus were found in patients with spina bifida in our study. These findings favor the results of a Turkish study showing CNS related anomalies as the commonest CA. ${ }^{16}$ CNS anomalies are considered the most common in live born and still born fetuses in Egypt and in other countries as well. ${ }^{17}$

Congenital heart defects (CHD), however, could not be documented in our study because children born with heart defects were transferred to the Lady Reading Hospital (LRH) Peadiatric Cardiology unit. In the future, we would like to do a study that includes congenital heart defects (CHD) to determine this frequency and other associated anomalies.

In this study, males were more commonly affected than females (1.2:1). Congenital malformations that exist more commonly in males have also been reported in other studies. ${ }^{17}$ Lisi reported that sex distribution varied significantly and that it depends on the type of malformation and whether it is isolated, associated with another malformation, or syndromic. ${ }^{18}$ As a result, sex distribution should be studied in every CA separately and not in the group of CAs as a whole.

Inter-cousin marriages are very common in countries with different religious and ethnic backgrounds. ${ }^{19}$ Pakistan has been noted to have the world's highest prevalence $(61 \%)$ of consanguineous marriages between first and second cousins. ${ }^{20}$
In our study, consanguinity was present in $67.7 \%$ of cases with various CAs. A study performed in Iran demonstrated that CAs were 3.5 times more common in consanguineous marriages as compared to non-consanguineous marriages. ${ }^{21}$

Furthermore, only $32.3 \%$ of the mothers had received folic acid or multivitamins. This may represent a lack of adherence to these dietary recommendations to avoid CAs. To reduce the occurrence of neural tube defects, it is recommended for all pregnant women to consume $400 \mathrm{mg}$ of folic acid daily. ${ }^{22}$

It has been suggested that the increasing age of mothers is associated with an increase in chromosomal meiotic errors and is probably the only non-genetic risk factor for trisomy in human beings. ${ }^{23}$ Mean maternal age in our study was $30 \pm 8$ years with only $19.4 \%$ of mothers above 40 years of age. Our results are similar to a study done in Iran (maternal age $25.69+5.54$ years, $8.7 \%>35$ years age).${ }^{19}$ Besides maternal age, multiparity and multigravidas are also associated with an increased prevalence of $\mathrm{CAs}^{24}$ Almost $70 \%$ of mothers in our study were multigravida, which is consistent with a study by Qazi that showed 2 out of 3 congenital malformations in newborns were associated with maternal multigravida. ${ }^{25}$ This is in contrast to a study by Perveen that demonstrated more CAs in primigravida mothers. ${ }^{16}$ Maternal age is an important parameter affecting the birth of a fetus with congenital malformations. For this reason, females who are older than 30 years of age need to be examined more carefully since the risk of giving birth to a fetus with congenital malformations is greater.

In our study, $77.6 \%$ of babies with CAs were found to have birth weights of $<2.5 \mathrm{~kg}$. A high frequency of birth defects was also reported in other studies that examined infants with low or very low birth weight, including premature infants.

Our findings are consistent with another local study showing that $43.5 \%$ infants birth weight of $<2.5 \mathrm{~kg}$ have congenital anomalies. ${ }^{28}$ Intrauterine growth restriction (IUGR) could be a primary predisposing factor for these anomalies or may occur secondarily as a result of existing CAs. It may even be that both IUGR and CAs may coexist with some common etiologic factors. ${ }^{26}$

No active smoking was present in our study; however, passive (second-hand) smoking during pregnancy was present in $16.1 \%$ cases. This is now an established fact that the risk of congenital malformation is significantly increased by passive second-hand smoke exposure during pregnancy. ${ }^{27}$ Other risk factors like teratogenic drug use were not that frequently discovered in our study.

One of the limitations of this study is that there is a well-known association between folic acid deficiency and neural tube defects. Serum and blood folate levels could not be determined due to their high cost. As a result, the definitive diagnosis of chromosomal abnormalities could not be made because of the lack of availability of these appropriate tests. Since this study was a cross-sectional descriptive study, the findings may not be projected to the entire population. Nevertheless, these results emphasize an important public health issue and present a baseline for other well-designed studies. 
Congenital anomalies are important causes of fetal deaths; thus, it becomes mandatory to determine the incidence and prevalence of congenital abnormalities in society. The present study demonstrated a high frequency of congenital malformations in the young age group and especially among primigravida women. The most frequently reported risk factor was consanguineous marriage. CNS malformations were the most prevalent anomaly detected. Early prenatal diagnosis is therefore very helpful in decreasing perinatal mortality by allowing for the option of early termination of pregnancy. This study contributes the frequency of congenital anomalies and the self-reported risk factors of congenital anomalies in a tertiary referral center in Pakistan. Further studies are required to evaluate interventions that may be oriented to eliminate risk factors and reduce the incidence of congenital anomalies. 


\section{References}

1. Boygle CA, Cordero JF. Birth defects and disabilities: a public health issue for the 21st century. Am J Public Health. 2005 Nov;95(11):1884-6

2. Singh A, Gupta RK. Pattern of congenital anomalies in newborn: a hospital based prospective study. JK Science. 2009 Jan-Mar;11(1):34-6.

3. Bittles AH. Consanguineous marriage: current global incidence and its relevance to demographic research. Ann Arbor(MI): University of Michigan, Population Studies Center; 1990. (Research Report No. 90-186)

4. Kumar MR, Bhat BV, Oumachigui A. Perinatal mortality trends in a referral hospital. Indian J Pediatr. 1996 May-Jun;63(3):357-61.

5. Korejo R, Bhutta S, Noorani KJ, Bhutta ZA. An audit and trends of perinatal mortality at the Jinnah Postgraduate Medical Centre, Karachi. J Pak Med Assoc. $2007 \mathrm{Apr} ; 57(4): 168-72$.

6. Kalter $\mathrm{H}$, Warkany J. Medical progress. Congenital malformations: etiologic factors and their role in prevention. N Engl J Med. 1983 Feb 24;308(8):424-31. 7. Costa CM, da Gama SG, Leal Mdo C. Congenital malformations in Rio de Janeiro, Brazil: prevalence and associated factors. Cad Saude Publica. 2006 Nov;22(11):2423-31.

8. von Elm E, Altman DG, Egger M, Pocock SJ, G $\phi$ tzsche PC, Vandenbroucke JP; STROBE Initiative. The Strengthening the Reporting of Observational Studies in Epidemiology (STROBE) statement: guidelines for reporting observational studies. PLOS Med. 2007 Oct 16;4(10):e296.

9. Rankin J, Pattenden S, Abramsky L, Boyd P, Jordan H, Stone D, et al. Prevalence of congenital anomalies in five British regions,1991-99. Arch Dis Child Fetal Neonatal Ed. 2005 Sep;90(5):F374-9.

10. Cul F, Jabin M, Khan AS. Frequency of congenital malformations and associated risk factors at Liaqat Memorial Hospital, Kohat. Khyber Med Univ J. $2012 ; 4(3): 119-24$

11. Perveen F, Tyyab S. Frequency and pattern of distribution of congenital anomalies in the newborn and associated maternal risk factors. J Coll Physicians Surg Pak. 2007 Jun;17(6):340-3.

12. Taksande A, Vilhekar K, Chaturvedi P, Jain M. Congenital malformations at birth in Central India: a rural medical college hospital based data. Indian J Hum Genet. 2010 Sep;16(3):159-63.

13. Movafagh A, Zadeh ZP, Javadi MH, Mohammed FM, Chaderian SM, Heidari $\mathrm{MH}$, et al. Occurrence of congenital anomalies and genetic diseases in a population of Chazvin Province, Iran: a study of 33380 cases. Pak J Med Sci. 2008 Jan-Mar;24(1):80-5.

14. Alberta Health and Wellness. Alberta Congenital Anomalies Surveillance
System: ninth report 1997-2009. Edmonton (AB): Alberta Health and Wellness; 2012.

15. Tomatir AG, Demirhan H, Sorkun HC, Köksal A, Ozerdem F, Cilengir N. Major congenital anomalies: a five-year retrospective regional study in Turkey. Cenet Mol Res. 2009 Jan 13;8(1):19-27.

16. Shawky RM, Elsedfy HH, Abolouz SK, Labatia GY. Prevalence of congenital malformations in a thousand consecutive Egyptian liveborn. Egypt J Med Hum Genet. 2001;2(1):43-53.

17. Khan SM, Ahmad CS, Abu-Talib A. Are congenital anomalies more frequent in Saudi Arabia? Ann Saudi Med. 1990;10:488-9.

18. Lisi A, Botto LD, Rittler M, Castilla E, Bianca S, Bianchi F, et al. Sex and congenital malformations: an international perspective. Am J Med Genet A. 2005 Apr 1;134A(1):49-57.

19. de Costa CM. Consanguineous marriage and its relevance to obstetric practice. Obstet Gynecol Surv. 2002 Aug;57(8):530-6.

20. Rukanuddin AR, Hasan KZ. Maternal and Child Health. In: Pakistan Demographic and Health Survey 1990/1991. Islamabad: National Institute of Population Studies; 1992. p. 125-48.

21. Mosayebi Z, Movahedian AH. Pattern of congenital malformations in consanguineous versus non consanguineous marriages in Kashan, Islamic Republic of Iran. East Mediterr Health J. 2007 Jul-Aug;13(4):868-75.

22. Centers for Disease Control and Prevention. Folate status in women of childbearing age, by race/ethnicity-United States, 1999-2000, 2001-2002, and 2003-2004. MMWR Morb Mortal Wkly Rep. 2007 Jan 5;55(51-52):1377-80.

23. Yoon PW, Freeman SB, Sherman SL, Taft LF, Gu Y, Pettay D, et al. Advanced maternal age and the risk of Down syndrome characterized by the meiotic stage of chromosomal error. a population based study. Am J Hum Genet. 1996 Mar;58(3):628-33.

24. Sipilä P, von Wendt L, Hartikainen-Sorri AL. The grand multipara-still an obstetrical challenge? Arch Gynecol Obstet. 1990;247(4):187-95.

25. Qazi G. Relationship of selected prenatal factors to pregnancy outcome and congenital anomalies. J Ayub Med Coll Abbottabad. 2010 OctDec;22(4):41-5.

26. Khoury MJ, Erickson JD, Cordero JF, McCarthy BJ. Congenital malformations and intrauterine growth retardation: a population study. Pediatrics. 1988 Jul;82(1):83-90.

27. Leonardi-Bee J, Britton J, Venn V. Secondhand smoke and adverse fetal outcomes in nonsmoking pregnant women: a meta-analysis. Pediatrics. 2011 Apr;127(4):734-41.

\section{Acknowledgments}

Dr Iftikhar Qayum, Research Department, Rehman Medical College, Peshawar, Dr Rashid Iqbal and Dr Ali Raza, Community Health Science Department, Rehman Medical College, Peshawar, Pakistan, and doctors and staff of Obstetrics \& Cynaecologiy Department, Khyber Teaching Hospital, Peshawar, Pakistan are acknowledged for their support and advice.

Conflict of Interest Statement a Funding

The Authors have no funding, financial relationships or conflicts of interest to disclose.

\section{Author Contributions}

Conception and design the work/idea: AK. Collect data/obtaining results, Analysis and interpretation of data: AK, MZ, FA, MF, ArK, JZ, HU, $\mathrm{RU}, \mathrm{SB}$. Write the manuscript: AK, MZ. Critical revision of the manuscript: AK. Approval of the final version: AK, MZ. Contribution of patients or study material, Obtaining financing: AK. Statistical advice: AK, MZ.

Cite as:

Khan A, Zuhaid M, Fayaz M, Ali F, Khan A, Ullah R, et al. Frequency of Congenital Anomalies in Newborns and Its Relation to Maternal Health in a Tertiary Care Hospital in Peshawar, Pakistan. Int J Med Students. 2014 Nov-2015 Mar;3(1):19-23. 